\title{
Association of agr Gene Expression with Staphylococcus aureus Virulence Genes in BHI Broth
}

\author{
Hadi Koohsari (PhD) \\ Department of Microbiology, Azadshahr \\ Branch, Islamic Azad University, \\ Azadshahr, Iran \\ Ezzat Allah Ghaemi (PhD) \\ Department of Microbiology, Golestan \\ University of Medical Sciences, Gorgan, \\ Iran \\ Nour Amir Mozaffari (PhD) \\ Department of Microbiology, Iran \\ University of Medical Sciences, Tehran, \\ Iran \\ Abdolvahab Moradi (PhD) \\ Department of Microbiology, Golestan \\ University of Medical Sciences, Gorgan, \\ Iran \\ Corresponding Author: Hadi Koohsari \\ E-mail: hadikoohsari@yahoo.com \\ Tel: +989112730361
}

Adderess: Department of Microbiology, Azadshahr Branch, Islamic Azad University, Azadshahr, Iran

Received : 20 Nov 2013

Revised: 10 May 2014

Accepted: 14 May 2014

\section{ABSTRACT}

Background and Objective: Agr is the most important regulatory system for the expression of Staphylococcus aureus virulence factors in different conditions. Agr acts as a quorum sensing system in this bacterium which is activated by increased cell concentration during the transition from exponential growth phase to stationary phase. Its role is to upregulate the secretory virulence factors such as alpha-hemolysin and inhibit the transcription of surface proteins including protein A-encoding gene. The aim of this study was to assess the relationship between the agr system expression and some virulence factors of Staphylococcus aureus in Brain-heart infusion (BHI) broth.

Methods: The expression level of agrA and RNAIII genes from the agr locus along with the expression of hla, spa and mecA genes in BHI broth were assessed in different growth phases using Real time-PCR. Also, gyrB was used as an internal control in this study.

Results: The growth curve of the five tested isolates in BHI broth at 24 hours showed that all the isolates had relatively similar growth patterns. AgrA gene expression in the stationary phase was decreased by 0.09 -fold compared with the exponential phase. Although the expression of RNAIII gene increased by 3-fold, hla expression decreased by 0.47 -fold.

Conclusion: An inactive agr system is observed in the BHI broth medium. BHI broth medium contains high amounts of suitable nutrients for the growth of Staphylococcus aureus, thus the bacteria do not require the activity of the agr system for the regulation of the virulence genes in these conditions.

Keywords: Staphylococcus aureus; agr; Virulence Factores; Growth Curve; BHI Broth. 


\section{INTRODUCTION}

Staphylococcus aureus ( $S$. aureus) is an opportunistic pathogen and one of the most important health problems in the world. It is a commensal microflora of almost $30 \%$ of the adult population (1). This bacterium is associated with a variety of human diseases ranging from benign skin infections to lifethreatening systemic diseases such as osteomyelitis, endocarditis, pneumonia, bacteremia, sepsis and toxic shock syndrome (2). The increasing emergence of Methicillinresistant S.aureus (MRSA) strains, which can cause problems such as nosocomial infections, has increased the importance of these bacteria (3). The ability of these bacteria to cause a wide range of diseases is related to expression of a large number of virulence factors. The most important system that regulates the expression of virulence factors in S.aureus is known as accessory gene regulator (agr), which is also the first known regulatory system in this bacterium (4). The agr is the intermediate of regulating more than 70 genes, 24 of which have been identified as virulence factors $(4,5)$. It is considered as a quorum sensing system in S.aureus that is activated following the increase of intracellular concentration during the transition from exponential phase to stationary phase of growth. It plays a regulatory role by increasing the transcription of genes involved in exoprotein production and toxin secretion such as the gene encoding alpha-hemolysin (hla), inhibiting the transcription of genes involved in binding of bacteria to host cells and evading the immune system such as protein a encoding gene $(s p a)(4,6)$. The agr locus consists of two operons, P2 and P3 which express two different transcripts. The P2 operon expresses RNAII transcript which contains four genes (agrA, agrB, agrC and $\operatorname{agrD}$ ) that encode four proteins. The activity of AgrB which is a membrane-bound protein, causes the secretion of AgrD, also known as the autoinducing peptide (AIP). Once sufficient quantities of the $\operatorname{agrD}$ (AIP) accumulates in the culture medium (usually during the transition from the exponential phase to the stationary phase), AgrC (a membrane-bound extracellular kinase that binds to the extracellular AIP) becomes activated. Following this activation, AgrC activates the main regulator (AgrA) through its phosphorylation. AgrA also operates to increase the transcription of RNAII and
RNAIII. P3 operon expresses RNA III transcript which acts as an effector molecule of the agr locus. RNAIII is a 510-nucleotide molecule that stimulates the transcription of genes encoding secretory toxins and enzymes, while inhibiting the transcription of surface protein-encoding genes. In addition to its regulatory role, RNA III acts as an mRNA for staphylococcal delta-hemolysin $(7,8)$.

This study aimed to investigate the gene expression level of agrA and RNAIII from the agr locus as well as the expression of hla, spa and mecA genes in five S.aureus isolates in BHI broth culture medium, during various growth phases. gyrB was also used as an internal control in this study.

\section{MATERIAL AND METHODS}

In this study, four $S$. aureus isolates were used, two of which were isolated from the nasal cavity of healthy volunteers (one MRSA and one MSSA) and the other two from patients (one MRSA and one MSSA). A standard S. aureus strain (COL) was also used in addition to these strains. The isolates were recovered and then was identified using conventional laboratory techniques including the Gram staining, catalase test, hemolysis on Blood agar and coagulase test. All the isolates were cultured on Blood agar for 24 hours at 37 ${ }^{\circ} \mathrm{C}$. Also, 2-3 identical colonies from each isolate were inoculated into $\mathrm{BHI}$ broth media. The samples were kept at $37{ }^{\circ} \mathrm{C}$ until their suspension turbidity reached $0.5 \mathrm{McF}$ arland standard $\left(1.5 \times 10^{8} \mathrm{CFU} / \mathrm{ml}\right)$.

The final suspension containing $10^{3} \mathrm{CFU} / \mathrm{ml}$ was prepared by repeated dilution. This concentration was considered as 0-time, inoculation time. These cultures incubated at $37^{\circ} \mathrm{C}$ in 24 test tubes which were sampled at hourly interval. Surface culture on Mueller Hinton agar medium was done and then the samples were incubated at $37^{\circ} \mathrm{C}$.

The number of colonies were counted after 24hour incubation. The total number of bacteria per hour was calculated by the following equation: The number counted colony $\times 1 /$ dilution index and the growth curve was plotted.After plotting the growth curves, bacteria from the exponential and stationary growth phases were used for RNA extraction and Real-time PCR. RNA extraction and purification RNA extraction was performed using the RNX-plus solution (CinnaGen Co.) according to the manufacturer's protocol. The 
quality and integrity of the obtained RNA was assessed using agarose gel electrophoresis and ethidium bromide staining to detect two $1.5 \mathrm{~kb}$ (16S) and 2.9 (23S) kb bands. In order to remove the residual amounts of DNA, RNasefree DNase I (Thermo Scientific) was used according to the Fermentas protocol. After choosing appropriate primers, Real-time PCR was performed using SYBR Green dye to assess the extracted level of the aforementioned RNA genes. The One-Step RT-PCR method was done using QuantiFast SYBR Green kit (Qiagen). RT-PCR was performed using an ABI Prism 7300 thermocycler (Applied Biosystems) and the level of targeted genes' expression in the extracted RNA samples from different isolates were normalized based on the $\operatorname{gyr} B$ gene as an internal control. Table 1 shows the list of used primers in this study which were obtained based on pairing location and length of the PCR product in NCBI website and using the Blast tool. The relative quantification method was used in this study to assess gene expression. Expression of the genes were compared with a reference gene as an internal control (gyrB). Experiment was replicated three times. After performing the PCR process, The computer software constracts amplification plots using the flurescence emmission data that are collected during the PCR amplification. A fluorescence signal that is detected above the threshold is considered a real signal that can be used to define the threshold cycle $\left(\mathrm{C}_{\mathrm{T}}\right)$ for a sample. The amount of targeted gene in samples was normalized using a housekeeping gene as an internal control $\left(\Delta \mathrm{C}_{\mathrm{T}}\right) . \Delta \mathrm{C}_{\mathrm{T}}$ is the $\mathrm{C}_{\mathrm{T}}$ of the target gene subtracterd from the $\mathrm{C}_{\mathrm{T}}$ of the housekeeping gene $\left(\Delta \mathrm{C}_{\mathrm{T}}=\mathrm{C}_{\mathrm{T}}\right.$,target $-\mathrm{C}_{\mathrm{T}}$, gyr $\left.B\right)$. It should be noted that lower $\Delta \mathrm{C}_{\mathrm{T}}$ levels indicate higher gene expression levels.

\section{RESULTS}

The growth curve of the five S.aureus isolates in BHI broth during the incubation period from the inoculation time ( 0 -time) up to 24 hours was plotted. Figure 1 demonstrates the growth curve of the five tested isolates in BHI broth in 24 hours which indicates that all of the isolates had relatively similar growth patterns (Figure 1).

Table 1- The list of primers used in this study

\begin{tabular}{|c|c|c|}
\hline Name & Sequence (5' to $\left.3^{\prime}\right)$ & Product size(bp) \\
\hline $\operatorname{agrA}(F)$ & TGA TAA TCC TTA TGA GGT GCT T & 163 \\
\hline $\operatorname{agrA}(R)$ & CAC TGT GAC TCG TAA CGA AAA & \\
\hline RNAIII (F) & CGA TGT TGT TTA CGA TAG CTT & 146 \\
\hline RNAIII $(R)$ & CCA TCC CAA CTT AAT AAC CA & \\
\hline hla $(F)$ & GGG GAC CAT ATG ATA GAG ATT & 154 \\
\hline hla $(R)$ & TGT AGC GAA GTC TGG TGA AA & \\
\hline spa $(F)$ & GAT GGT AAC GGA GTA CAT GTC GTT & 163 \\
\hline spa $(R)$ & TTG CTG GTT GCT TCT TAT CAA CA & \\
\hline $\operatorname{mec} A(F)$ & ACT GCT ATC CAC CCT CAA AC & 165 \\
\hline $\operatorname{mec} A(R)$ & CTG GTG AAG TTG TAA TCT GG & \\
\hline $\operatorname{gyr} B(F)$ & CGC AGG CGA TTT TAC CAT TA & 141 \\
\hline $\operatorname{gyr} B(R)$ & GCT TTC GCT AGA TCA AAG TCG & \\
\hline
\end{tabular}

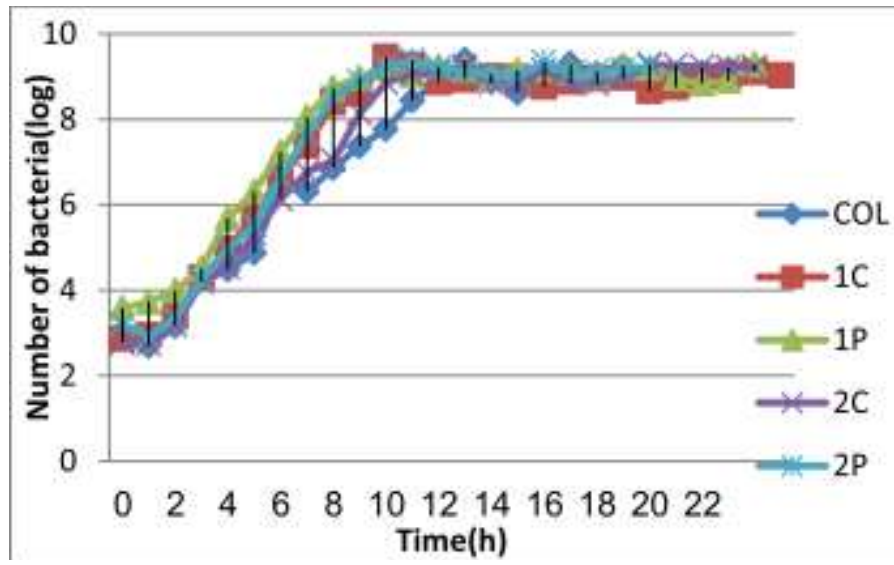

Figure 1- Growth curves of the five tested S.aureus isolates in BHI broth medium. All isolates had relatively similar growth patterns. Standard isolate (COL), clinical isolate MRSA (2P), clinical isolate of MSSA (1P), carrier isolate MRSA (2C), carrier isolate MSSA (1C). 
The results showed that the doubling time of the standard strain (COL) was higher than the other strains. MRSA isolates showed higher doubling times compared to other MSSA isolates. Also, the mean doubling time of the clinical isolates was lower than the healthy carriers. The required time for division of the standard strain (COL), methicillin resistant clinical isolate (2P), methicillin-susceptible clinical isolate (1P), methicillin-resistant carrier isolate $(2 \mathrm{C})$ and methicillin-susceptible carrier isolate (1C) was $31.88,24.52,21.39$, 27.07 and 22.07 minutes, respectively.

The device software showed the $\mathrm{C}_{\mathrm{T}}$ of the studied genes in the five $S$. aureus isolates and then $\Delta \mathrm{C}_{\mathrm{T}}$ was calculated based on the gyrB gene (internal control) (Table 2).

Figure 3 shows the mean $\Delta \mathrm{C}_{\mathrm{T}}$ of different genes in the exponential and stationary phase.

Since lower numerical amount of $\Delta C_{T}$ indicates increased gene expression, it can be concluded that gene expression of agrA and hla was decreased in the stationary phase and in contrast, RNAIII, spa and mecA genes showed higher expression levels in the stationary phase (Figure 3).

The level of agrA gene expression in total of the five isolates showed a 0.89 -fold increase during the transition from exponential phase to stationary phase. Whereas, the other regulatory gene of the agr system (RNAIII) showed a 3fold increase in total of the five isolates in stationary phase compared to the exponential phase.

The gene expression of hla gene (alphahemolysin-encoding gene) showed a 0.47 -fold decrease in the stationary phase. Spa gene (protein A-encoding gene) was evenly expressed in the exponential and stationary phase and had a 1.1-fold expression increase in the stationary phase. A 2.8 -fold increase was observed in the case of mecA gene (methicillin-resistance encoding gene). Spa gene was expressed 2 times more in the clinical isolates compared with the carrier isolates, while agrA gene was 0.35 -fold underexpressed. Also, the overexpression of hla and RNAIII genes in the clinical isolates was not significant when compared to the carrier isolates.

Table 2- $\Delta \mathrm{C}_{\mathrm{T}}$ of the five $S$. aureus isolates genes in the exponential and stationary phases in BHI broth

\begin{tabular}{|c|c|c|c|c|c|c|c|c|c|c|}
\hline \multicolumn{2}{|c|}{$1 \mathrm{C}$} & \multicolumn{2}{|c|}{$1 \mathrm{P}$} & \multicolumn{2}{|c|}{$2 P$} & \multicolumn{2}{|c|}{$2 \mathrm{C}$} & \multicolumn{2}{|c|}{ COL } & \\
\hline STA & EXP & STA & EXP & STA & EXP & STA & EXP & STA & EXP & \\
\hline 0.93 & 0.56 & 1.51 & 0.88 & 2.96 & 3.3 & 0.54 & 0.61 & 3.46 & 3.24 & $\operatorname{agr} A$ \\
\hline 2.06 & 3.58 & -1.12 & 1.99 & 2.49 & 4.8 & 1.47 & 1.68 & 6.42 & 7.15 & RNAIII \\
\hline 1.52 & 0.75 & 1.62 & -0.11 & 1.1 & 0.56 & 2.5 & 0.19 & 3.8 & 3.73 & Hla \\
\hline-0.73 & 0.15 & -2 & -0.34 & -0.83 & -0.44 & 1.03 & 0.18 & 5.79 & 4.44 & Spa \\
\hline MSSA & MSSA & MSSA & MSSA & 0.96 & 1.85 & 8.8 & 11.75 & -1.27 & -0.67 & mecA \\
\hline
\end{tabular}

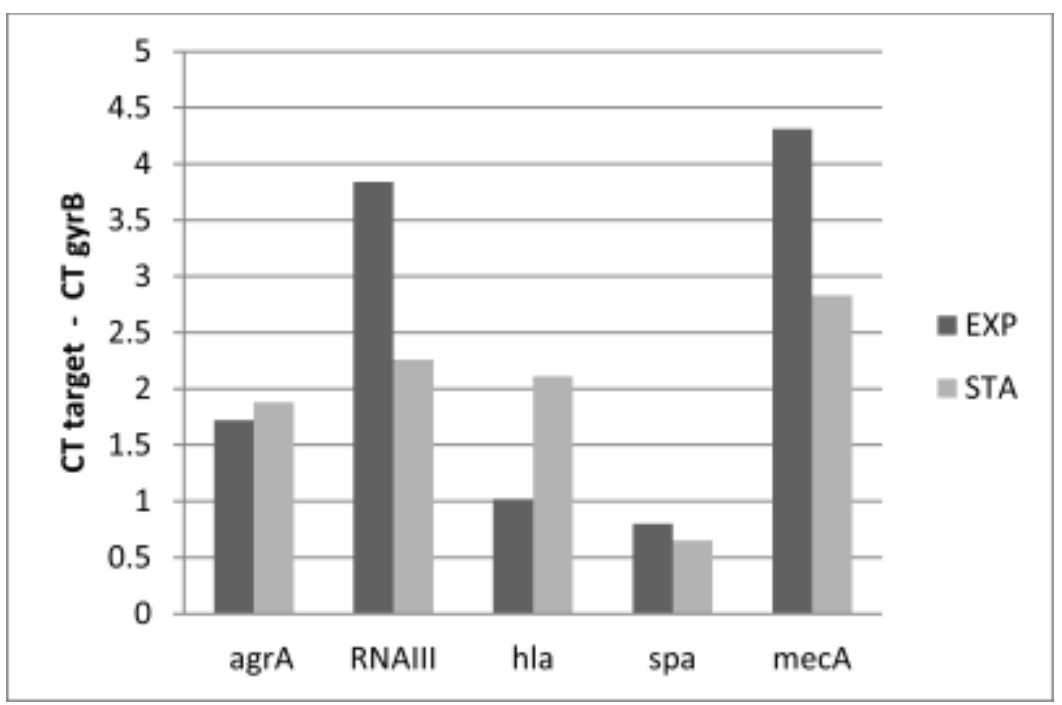

Figure 3 - Mean $\Delta C_{T}$ of different genes in the exponential and stationary phase in BHI broth 


\section{DISCUSSION}

One of the aims of this study was to investigate the growth curve patterns of different $S$. aureus strains in BHI broth medium. As it was shown in Figure 1, the tested $S$. aureus isolates in this study had relatively similar growth patterns. Although the growth rate of COL standard strain was lower than other strains, eventually they all showed similar growth patterns. The findings of Laurent and Orozgani in two separate studies showed that MRSA isolates have longer doubling time compared with MSSA isolates which is in agreement with our findings $(11,10)$. MRSA strains contain the mecA gene that encodes PBP2A protein which is replaced on the bacterial surface and possibly prevent the entry of nutrients into the cells. If this theory is correct, the difficult entry of drugs and disinfectants into the MRSA isolates, ultimately making them more resistant to these compounds compared to the MSSA isolates is justified. Assessing the growth curve of the isolated $S$. aureus strains also showed that the isolated samples from healthy carriers had longer generation time compared to the clinical isolates. This is consistent with the results of Chen et al. which showed that the average doubling time for $S$. aureus isolates from nose of healthy subjects were higher compared to the clinical isolates (12). An inactive agr system is observed in BHI broth medium because despite our expectations, the regulator of the agr reaction $(\operatorname{agr} A)$ is less expressed during the transition from the exponential phase to the stationary phase. Even the expression of RNAIII was unable to exert regulatory effects on the hla gene as evidenced by the 0.47 -fold decreased expression this gene in the stationary phase.

\section{REFERENCES}

1. Kuehnert MJ, Kruszon-Moran D, Hill HA, McQuillan G, McAllister SK, Fosheim G, et al. Prevalence of Staphylococcus aureus nasal colonization in the United States, 2001-2002. J Infect Dis. 2006; 193(2): 172-9.

2. Gordon RJ, Lowy FD. Pathogenesis of methicillinresistant Staphylococcus aureus infection. Clin Infect Dis. 2008; 46(5): 350-9.

3. Diep BA, Otto M. The role of virulence determinants in community-associated MRSA pathogenesis. Trends Microbiol. 2008;16(8): 361-369.

4. Caetano L, Antunes M, Rosana B, Ferreira R, Michelle M, Buckner C, et al. Quorum sensing in bacterial virulence. Microbiology. 2010; 156: 22712282. doi: 10.1099/mic.0.038794-0
As expected, the methicillin-resistance gene (mecA) was increased by 2.8 times compared to the exponential phase in these conditions. However, the spa gene expression change was not significant (Figure 4). These are in all agreement with Oogai et al. findings which showed that in Trypticase soy broth (TSB), RNAIII regulatory gene was overexpressed in the stationary phase, while accompanied by decreased expression of some virulence genes such as aur (aerolysin-encoding gene) and Panton-Valentine, with no change in their expression in the stationary phase in optimal conditions (13). The probable reason for this could be that in BHI broth, bacteria do not isolates, while $h l g$ gene expression in the invasive isolates was higher than the colonized isolates. This group concluded that the origin of isolation cannot be involved in its pathogenicity without considering other genetic factors related to the isolate (18), which could explain the differences between our study and AbuOthman.

\section{CONCLUSION}

As mentioned previously, gene expression varies depending on the growth conditions. Therefore, assessing the gene expression in clinical conditions is recommended in order to obtain a more thorough understanding of virulent genes' expression and the effect of $a g r$ gene on patients and healthy carriers.

\section{ACKNOWLEDGMENT}

The non-stop efforts of microbiology laboratory staff of Golestan University of Medical Sciences, especially Ms. Seyyedeh Naemeh Javid and Mr Masoud Bazoory are appreciated for their assistance in conducting this research.

\section{CONFLICT OF INTEREST}

Therer are no conflicts of interest.

5. George EA, Muir TW. Molecular mechanisms of agr quorum sensing in virulent staphylococci. Chem Bio Chem. 2007; 8(8): 847-855.

6. Dunman PM, Murphy E, Haney S, Palacios D, Tucker-Kellogg G, Wu S, et al. Transcription profilingbased identification of Staphylococcus aureus genes regulated by the agr and/or sarA loci. J Bacteriol. 2001; 183(24): 7341-53.

7. Gov Y, Borovok I, Korem M, Singh VK, Jayaswal RK, Wilkinson BJ, et al. Quorum Sensing in Staphylococci Is Regulated via Phosphorylation of Three Conserved Histidine Residues. Journal of Biological Chemistry. 2004; 279(15): 14665-14672.

8. Novick RP, Geisinger E. Quorum sensing in staphylococci. Annu Rev Genet. 2008; 42: 541-64. doi: 10.1146/annurev.genet.42.110807.091640. 
9. Arya M, Shegill IS, Williamson M, Gommersall L, Arya N, Patel HRH. Basic Principles of Real-time quantitative PCR. Expert Rev Mol Diagn. 2005; 5(2): 209-219.

10. Laeurent F, Lelievre $\mathrm{H}$, Conu $\mathrm{M}$, Vandenesch $\mathrm{F}$, Carret G, Etienne J, et al. Fitness and competitive growth advantage of new gentamicin-susceptible MRSA clones spreading in French hospitals. Journal of Antimicrobial Chemotherapy. 2001; 47(3): 277-283.

11. Rozgonyi F, Kiss J, Kristof K, Nagy K. Is MRSA more virulent than MSSA? Clin Microbiol Infect. 2007; 13(9): 843-845.

12. Chen FJ, SiuL KK, Lin JC, Wang CH, Lu PL. Molecular typing and characterization of nasal carriage and community-onset infection methicillin-susceptible Staphylococcus aureus isolates in two Taiwan medical centers. BMC Infectious Diseases. 2012; 12: 343-351. doi: 10.1186/1471-2334-12-343.

13. Oogai Y, Matsuo M, Hashimoto M, Kato F, Sugai M, Komatsuzawa H. Expression of Virulence Factors by Staphylococcus aureus Grown in Serum. Appl Environ Microbiol. 2011; 77(22): 8097-8105. doi: 10.1128/AEM.05316-11.
14. Regassa LB, Novick RP, Betley MJ. Glucose and nonmaintained $\mathrm{pH}$ decrease expression of the accessory gene regulator (agr) in Staphylococcus aureus. Infect Immun.1992; 60(8): 3381-8.

15. Malachowa N, Whitney AR, Kobayashi SD, Sturdevant DE, Kennedy AD, Braughton KR, et al. Global Changes in Staphylococcus aureus Gene Expression in Human Blood. PLoS ONE. 2011; 16(4): 113.

16. Rasmussen G, Monecke S, Ehricht R, Söderquist B. Prevalence of Clonal Complexes and Virulence Genes among Commensal and Invasive Staphylococcus aureus Isolates in Sweden. PLoS ONE. 2013; 8: e77477. DOI: 10.1371/journal.pone.0077477.

17. O'Donnell S, Humphreys H, Hughes D. Distribution of virulence genes among colonizing and invasive isolates of meticillin-resistant Staphylococcus aureus. Clin Microbiol Infect. 2008; 14(6): 625-626.

18. Abu Othman A, Humphreys H, O'Neill E ,Hughes DF. Differences in expression of virulence genes amongst invasive and colonizing isolates of meticillinresistant Staphylococcus aureus. Journal of Medical Microbiology. 2011; 60(2): 259-61. 